\title{
A Study on Application of the Behaviourial Finance in Investment Decisions
}

\author{
Nirmal Kumar Routra (Asst.Prof. Finance, Srusti Academy of Management) \\ Ananta Sahu (Asst.Prof. Finance, Srusti Academy of Management)
}

\begin{abstract}
Financial markets are influenced by various factors but the most important factors is the reaction as well as perception of the people. Basically there are two discipline of financial market study i.e., Traditional finance and the new development called Behaviourial finance.Traditional finance foundation is truly based on efficient market concept\&Behavioral finance argues that some financial phenomena can plausibly be understood usingmodels in which some agents are not fully rational. The field has two building blocks: limits toarbitrage, which argues that it can be difficult for rational traders to undo the dislocations caused byless rational traders; and psychology, which catalogues the kinds of deviations from full rationalitywe might expect to see. We close by assessing progress in the fieldand speculating about its future course. In this paper an attempt has been made to highlight the shortcomings of the traditional finance theories as pointed out by behavioural finance supporters and also a discussion on the significance of behavioural finance. While conventional academic finance emphasizes theories such as modern portfolio theory and the efficient market hypothesis, the emerging field of behavioral finance investigates the psychological and sociological issues that impact the decision-making process of individuals, groups, and organizations. This paper will discuss some general principles of behavioral finance including the following: overconfidence, financial cognitive dissonance, the theory of regret, and prospect theory. In conclusion, the paper will provide strategies to assist individuals to resolve these "mental mistakes and errors" by recommending some important investment strategies for those who invest in stocks and mutual funds.
\end{abstract}

Keywords: Behaviourial Finance, Investment decision making power of individuals, EMH.

\section{INTRODUCTION}

"People in standard finance are rational. People in behavioral finance are normal."

- Meir Statman. Global financial markets are influenced by many elements like the economic processes that take place in every country and the world, institutional and political constraints, information dissemination and accessibility etc. Overall, one of the most important aspect is the people's reaction and perception towards investment while taking decision-making process. Finance is basically about to precise investment decision, working capital decision, dividend decision and fund allocation and their disbursement. But economics is about decision making as to what to produce, how to produce and for whom to produce. The emerging field of behavioral finance also deals with the complex activity of decision making. Though the fields of economics and finance have contributed many theories over the years, it could not explain why people sometimes take irrational financial decision. Different theories were also developed in this context. Basically these developments are classified into three broad categories, viz. Traditional Finance theories, Modern Finance theories, and the latest addition is the Behavioural Finance theories. In this paper an attempt has been made to lighten the development of the Behavioural finance and will also discuss a few behavioural finance principles and their significance in the financial market study. The belief of behavioral finance is to study the irrational minds of investors. In this real world, the investor does not act as the rational one, but rather an irrational or quasi-rational manner. Thus, the different field of behavioral finance explains that behavior and psychological aspects while taking the investment decision.

\section{LITERATURE REVIEW}

The Behavioral theory showing the influence of human behaviour on investing decision emerges not as a supplementary assumption, but as a contradictory approach. In this part of literature review, an attempt is made to present a brief review of relevant research studies carried out on the behavioral finance and its impact on Investment decision making. Lewellen (1977) through a research work concluded that age, sex, income and education affect investors' preferences. Bogle (1992) analyzed that selection of fund by investors is based on the past performance of the funds and money flows into winning funds more rapidly than they flow out of losing funds. Shefrin's (2001) 
analyzed that Behavioral Finance is the study of impact of psychology on financial decision-making. Phillip (1995) analyzed the changes in financial decision-making and investor behavior after participating in investor education programs. In India, SEBI organizes awareness program for small investors, which has started giving benefits, in terms of value investing and informed investing from retail investors. Madhusudhan and Jambodekar (1996) concluded that investors expect better services from the Company where they invest. The majority of investors invest for safety of principal, liquidity and capital gain. Sewell (2005) concluded that Behavioural finance is the study of the influence of psychology on the behaviour of financial practitioners and the subsequent effect on markets. Tavakoli (2011) inspected the different factors influencing the decision of the investors. He analyzed the 13 factors to determine whether the investors consider these factors and decisions are influenced by these factors. He found that some of these factors are more influencing including financial statement, consulting with anybody, second hand information resources, financial ratios, reputation of the firm, profitability variable. Most important sub variable of profitability is thedividend.Kadariya (2012) investigated factors impact on the investor decision. These factors include capital structure, political and media coverage, luck and financial education and trend analyses in the Nepalese capital market. He concluded that majority of the investors are youngsters and they take decision considering the media coverage and friends recommendations as good source of information.

\section{OBJECTIVE OF THE STUDY:}

1. To highlight the difference between traditional market vs behavioral finance.

2. To study the growth of behaviourial finance.

3. To analyse the perception of small investors towards Behaviourial finance.

\section{RESEARCH METHODOLOGY}

The paper is purely conceptual and descriptive in nature. We have been collected the data from different research papers, journals, articles related to behaviourial finance from internet.Various other related books which are available in physical format are also considered for the development of this paper.

\section{GROWTH \& STRATEGIC IMPLICATION OF BEHAVIOURALFINANCE IN FINANCIAL MARKETS:}

According to Albert Einstein, "Only two things are infinite, the universe and human stupidity, and not sure about the former" seems to be many more relevant. In fact the human mind is the greatest and it is also the worst in some cases. History of the behavioral finance goes back to Herbert A Simon, the Nobel lieutenant of 1978, for his paper in 1955
-A behavioral model of rational choice may be regarded as the first thought that state about a new concept called behavioral finance. The risk of how some people make investment decisions is often more significant than the risk of the investment itself. The study of behavioural finance has grown significantly over the last several decades. Have you ever asked yourself what you need to know in order to be a successful investor? Part of that answer might be to better understand your natural tendencies, and to avoid common human mistakes. Most of investors think that investing is the domain of economists and mathematicians. Those disciplines have their role, however successful investing requires an understanding of human tendencies or mind. Financial theory suggests investors are risk adverse. They avoid taking on excess risk and buy or sell investments in order to less risk. However behavioural finance has observed this is not always the case. In the real world investors who are facing a potential loss will often take on additional risk in the hope that they will recover that loss. Even when the best strategy is to sell, they continue to hold the investment. The opposite is true when the investor has a gain. Those investors are risk adverse and are more likely to sell at a profit vs risk continuing to own that investment. For example, assume one investor purchased two separate investments. One appreciated by $20 \%$ and the other declined in value by $20 \%$. Logically the decision to continue to hold or sell each investment would be based on the investor's expectations of future changes in value of each investment. In a perfect world the correct decision would be made. Investing is no different than other aspects of life and long-term success is often based on making correct individual decisions over time. Success in investment is difficult. After tax, after investment fees, and after inflation, it is very difficult for most investors to achieve the amount of returns they had hoped for. In addition to that difficulty, the fact that human behaviour is not always logical makes achieving long-term investment success even more difficult. It is recommended to accept human tendencies as fact and try to develop strategies that will help you resist poor investment choices based on normal human behaviour. The key is to accept the fact that you too share these human tendencies, versus being in denial and thinking you are different. You are different as an individual however financial research would suggest most humans make this mistake. Another human tendency is to overstate the amount of risk they can tolerate. This may be dangerous during periods of stock market volatility. Human behaviour will play an important role in your longterm investment success. Behavioral Finance is the field which studies the investor's behavior not only from the point of view of rationality but also incorporating different other irrational psychological investment biases which are overlooked by the conventional finance completely. This new field incorporated the theories of psychology, sociology and also neurology in the study of investor behaviour. It may be noted that the behavioral finance is 
itself is not an original development. It is due to the shortcomings of the efficient market hypothesis and other conventional finance developments that the growth of behavioral finance is accelerated. As stated under the traditional financial theory, the decisions makers are assumed to be rational. In contrast, behavioural finance suggests that Investors financial decision-making are not driven only by the equilibrium models and they often prove to be irrational while making investment decisions. In other words as per the principles of behavioural finance human decisions are subject to several cognitive and emotional illusions. Some of those illusions can be grouped as follows:

Cognitive Dissonance: It states the mental discomfort felt by an investor while taking any investment decision.

Herd Behaviour: Herd indicates a group and in financial market context it implies to follow a trend of a group in respect of decision making. Many times investors knowingly or unknowingly disclose this type of behavior.

Loss Aversion: Aversion means the feeling of dislike or disinclination and loss aversion means disliking or feeling uncomfortable about a loss. This psychological feeling was first proclaimed by Kahneman and Tversky (1979) in their famous prospect theory.

Mental Accounting \& Ethics: Mental Accounting; a concept was developed by Richard Thaler in an attempt to describe the way in which a person subjectively frames a transaction in their mind the utility they receive or expect.

The supporters of EMH (Efficient Market Hypothesis) suggest that biases do not impact markets and any anomalies will always automatically be adjusted to drive stocks to their fundamental prices. According to them, the changes in the market happen for a variety of reasons and cannot be attributed to behavioral biases. They believe that if we sufficiently analyze any stock and read past trends and current news, it'll be easy to find that the market changes are just a matter of chance and not a product of individual behaviors. Presence of anomalies in the financial markets was the reason why behavioral finance came in to the picture. The behavior of these anomalies continue to violate the fundamental behavior of the financial markets which assumes that all investors are rational and logical. These anomalies can be summarized as follows:

- January Effect - Average monthly return for a small firm is uniformly higher in January than any other month in the year which is completely opposing to the efficient market hypothesis.

- Winner's Curse - Traders or gamblers tend to pay more than the true value of the asset in auction bids. This is against the EMH which suggests that investors will be aware of the true value of an asset and will pay or bid according to that.

- Equity Premium Puzzle - Conventional theorists suggest that the equity premium for stocks should be much lower than what is currently prevalent in the market. However, behavioral finance suggests that loss aversion bias requires high premium to over compensate investors for their aversion to loss.

Proponents of behavioral finance suggest that while most of these biases will not be simultaneously present in all investors, some or the other bias will be prevalent impacting the financial market in general. For example, heuristic biases such as representativeness and anchoring may make investors over optimistic about stocks that have performed well in the past and over pessimistic about stocks that have performed poorly in the given time frame, thus causing the actual share prices to deviate from their fundamental prices. These biases can lead to several issues that can be listed down as follows:

- Over or under reactions to any news about changes in price

- Ignoring the information regarding the fundamentals of stock price

- Using past trends to extrapolate future trends

- Undue preference to 'hot stocks'

\section{A YARDSTICK FOR THE FINANCE}

Behavioural finance discipline has come to an existence as a result of the shortcomings researched out of the efficient market theory and traditional finance theory. This development was highlighted the different anomalies of securities market behaviour which are overlooked by the traditional finance theories. But it is to be noted that both efficient market theory and behavioural finance are related to investor behaviour, i.e. how the investors make decisions regarding investment in securities market. We can say that if the biases put forwarded by the behavioural finance are given due consideration by the investors while making investment decisions then their decisions would be more efficient and this in turn will build their confidence about investment knowledge. This efficiency in investment decisions would also reduce the bubbles and crisis situations in financial market as seen every now and then in the stock market. Such bubbles and crisis vulnerabilities discourage the new investors to come out and invest. So if such situations are controlled, which is possible by following the behavioural finance principles would definitely bring more investors to the securities market. So although not directly but indirectly behavioural finance would definitely help to raise finance in the financial market through financial instruments.

\section{RECENT TRENDS IN THE FIELD OF INVESTOR'S BEHAVIOURAL FINANCE:}

Behavioural finances are more related to analysis of non- 
impossible to separate market influence and involve psychological factors that analyses their treatment in financial markets. The current trend says it is the increased interest in the profits gained via financial transactions. One of the most significant studies appeared in 1998, De Bondt concise that most of the people tend to forget the general principles of investment theory in the investment process (do not use the beta coefficient of systematic risk assessment) and are guided by intuition and other criteria that conflict with rational theory. In addition, it is noted that accumulated investment experience of the investor has no significant effect on the amount of errors, as a result, it may seem that there is no rational investor behaviour appeared in point of popped up information.
Traditional finances fall into the following basic paradigms:

a) portfolio is based on the expected return andrisk,

b) is subject to risk based capital asset pricing models, such asCAPM,

c) the pricing of contingentclaims,

d) Modigliani-Miller theorem.

All of these ideas came from investor rationality. However, the traditional finance does not respond to the questions:

a) Why does an investor trades?

b) How does an investor trades?

c) How an investor does composes portfolios?

d) And, finally, why do stock returns vary no due to the risk?

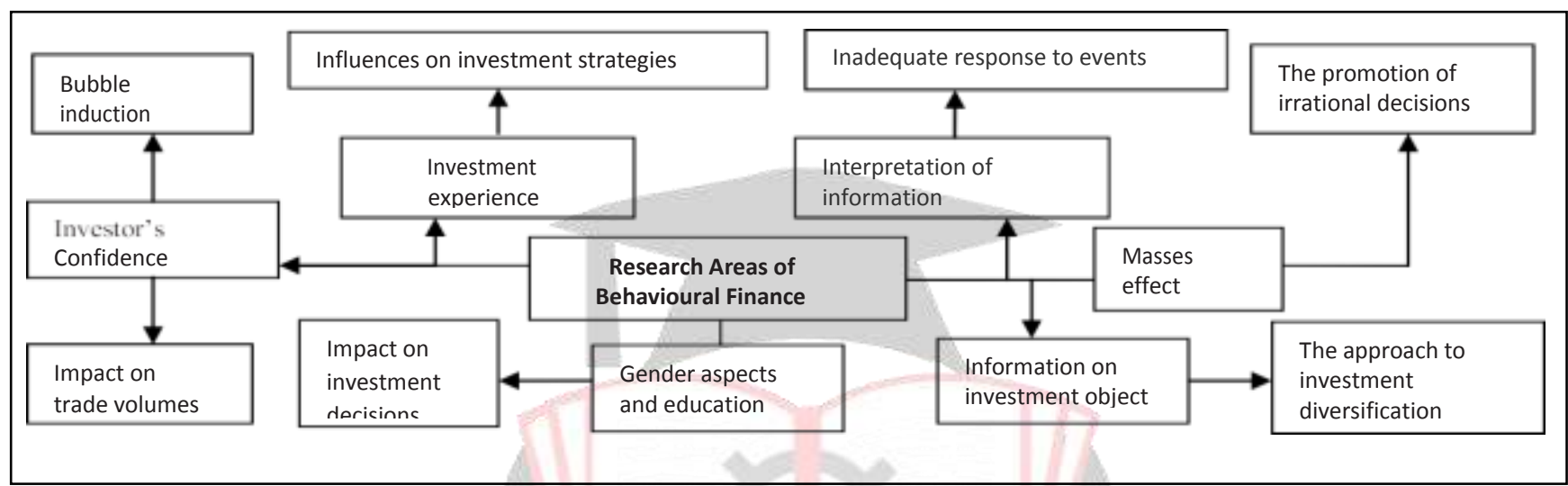

TRADITIONAL FINANCE VS BEHAVIORAL FINANCE:

The key difference between the traditional finance and behavioral finance are as follows:

\section{TRADITIONAL FINANCE}

- Assumes that people process data approximately and correctly.

- Presupposes that people view all decisions through the transparent and objective lens of risk andreturn.

- Assumes that people are guided by reasons and logic and independentjudgment.

- Argues that markets are efficient implying that the price of each security is an unbiased estimate of its intrinsic value.

\section{BEHAVIORAL FINANCE}

- It recognizes that people employ imperfect rules of thumb to process.

- It recognizes that emotions and heard instincts play an important role in influencing decisions.

- It suggests that the perceptions of risk and return are influenced by how decisions problem isframed.

- Argues that there is lack between market price and fundamental value are often caused by behavioral biases and errors, frame dependence effects, emotions and social influences.

- It arrives that prices are pushed by investors to unsustainable levels in both directions.

\section{FINDINGS \& SUGGESTIONS}

While it isn't possible for investors to completely let go of such biases and have the inherent realization that such biases are present, a few things can be kept in mind to ensure rational decision making that maximizes returns and minimizes their loss.

- Awareness: Well-read investors that are aware of the biases present while making investments are in a better position to tackle suchbiases.

- Find Data: Investors aren't alone in the market. It's important to find out sources that think differently than they do and then correspond data and reasoning with them to come to a conclusion. Chances are that the investor will end up making a much more informeddecision.

- Diversify: A great investor will always diversify. As the old saying goes, 'don't put all your chickens in one basket'. Diversification across industries and sectors ensures that investors realize higher returns while at the same time minimize risk of losing their entireinvestment. 
- Investment Goals: It's important that individuals realize and quantify their investment goals before leaping on to the investment bandwagon. This gives clarity of thought and helps investors avoid behavioral biases while making short-term changes for achieving those long- termgoals.

- Analyze Trends: While past 'winners' seem to be a good choice for investing, the law of long- term averages tends to ensure that last year's best performing assets may not perform that well this year. Hence, it's important to not place undue importance on past performance and expect the success to continue in the current year aswell.

- Track Mistakes: Everybody ends up making errors. Traders and investors may find themselves at the bottom of the pit multiple times and may feel that this is it. However, it's important to learn from those mistakes and get back on track keeping in mind the learnings so as to avoid the same in the future.

\section{CONCLUSIONS}

Traditional finance theorists and behavioral finance economists are constantly at loggerheads with each other. While much has been said and written about behavioral finance as a field, there is no formal one writing that has been able to completely identify and conclude that stock market anomalies are a by-product of behavioral biases. However, many important literature studies have been done in this field including some the field of behavioral finance has grown considerably in the past decade. That said, it does not negate the efficient market hypothesis completely. It does, however, give several possible reasons as to why anomalies occur in an efficient market and why stock prices divert from their fundamental values. Behavioral financial theories are extremely important for individual investors since biases in behavior and psychological differences play a key role in investment decision making process.

To conclude we can say that we must recognize the shortcomings of conventional finance put forwarded by the empirical findings, and at the same time an objective analysis is necessitated to arrive at a conclusion. The growth of behavioural finance in this regard is definitely a positive aspect to better study the investor behaviour. However the behavioural finance alone cannot be said to be a perfect one because the discipline is not too old to accept as a theory. And the behavioural finance is only a collection of ideas and thoughts which are descriptive and advisory in nature but they are not exhaustive. More discussions and studies are required to point the limitations of behavioural finance itself so as to refine it to be a good theory. Behavioural finance is based on research of human and social recognition and emotional tolerance studies to identify and understand incoming economic decisions. Behaviour finance examines recognition and emotional the limited human rationality, explains the psychology effect on the financial activities and argues that financial phenomena can be better explained due to the fact that financial market participants are not rational and their decisions are limited.

\section{REFERENCES}

[1] International Journal of Civil Engineering and Technology (IJCIET)

[2] Volume 9, Issue 6, June 2018, pp. 1151-1157, Article ID: IJCIET_09_06_130

[3] https://www.investopedia.com/terms/i/investment.asp

[4] https://www.investopedia.com/articles/stocks/09/indianstock-market.asp

[5] International Journal of Management Studieshttp://www.researchersworld.com/ijms/

[6] International Journal of Business and Management Invention ISSN (Online): 2319 - 8028,

[7] Kahneman, D. (2011) Thinking, fast and slow. New York, Farrar, Straus and Giroux.

[8] Montier, J. (2002) Behavioral Finance: Insights into Irrational Minds and Markets, WILEY, Chichester, West Sussex, England.

[9] Pompian, M. (2006) Behavioral Finance and Wealth Management: How to Build Optimal Portfolios That Account for Investor Biases, WILEY, New Jersey, USA.

[10] Shefrin, H. (2002) Beyond Greed and Fear: Understanding Behavioral Finance and the Psychology of Investing, Oxford University Press, New York, USA.

[11]Shefrin, H. (2007) Behavioral Corporate Finance: Decisions that Create Value, McGrawHill/Irwin, New York, USA.

[12] Shiller, R. (2005) Irrational Exuberance, Second Edition, Princeton University Press, USA.

[13] Taleb, N. (2004) Fooled by Randomness -The Hidden Role of Chance in Life and in the Markets, Penguin Books, London, England.

[14] Taleb, N. (2007) The Black Swan -The Impact of the Highly Improbable, Penguin Books, London, England. 